\title{
Periampüller bölge tümörlerinde ERKP ile suprapapiller koledok kanülasyonu
}

\author{
Suprapapillary choledochus cannulation of periampullary tumors with ERCP
}

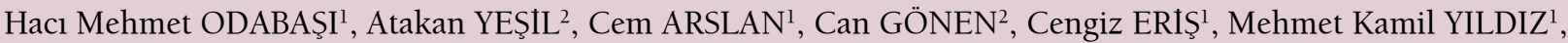
Hacı Hasan ABUOĞLU ${ }^{1}$, Emre GÜNAY ${ }^{1}$, Erkan ÖZKAN ${ }^{1}$, Tolga MÜFTÜOĞLU ${ }^{1}$

Haydarpaşa Numune Eğitim ve Araşsırma Hastanesi ${ }^{1}$ Genel Cerrahi Kliniğĭ ${ }^{2}$ Gastroenteroloji Kliniği, Istanbul

Giris ve Amaç: Endoskopik retrograd kolanjiopankreotografi biliyer hastalıkların tanı ve tedavisinde altın standarttır. Başarılı bir endoskopi için ana safra kanalına girmek en önemli basamaktır. Transkapiller kanülasyon tercih edilen yöntem olmakla birlikte her zaman başarı sağlanamamaktadır. $\mathrm{Bu}$ nedenle alternatif olarak suprapapiller kanülasyon tekniği geliştirilmiştir. Gereç ve Yöntem: Hastanemiz endoskopik retrograd kolanjiopankreatografi ünitesinde periampüller tümörlü ve kolanjitli 6 hastaya suprapapiller kanülasyon yapıldı. Bulgular: Hastalarda minör veya majör komplikasyon görülmedi. Sonuç: Özellikle periampüller tümörlü hastalarda transpapiller kanülasyonda zorluk yaşarsanız, suprapapiller kanülasyon tekniği kolay ve güvenli bir yöntemdir.

Anahtar kelimeler: ERKP, periampüller tümör, suprapapiller kanülasyon

\section{GİRISS}

Endoskopik retrograd kolanjiopankreatografi (ERKP), biliyer hastalıkların tanı ve tedavisinde yaygın olarak kullanılmaktadır. Başarılı bir terapötik endoskopi için ana safra kanalına doğruca girmek en önemli basamaktır. Hastalarda kanülasyon başarısı, hasta seçimine, özel kateterlerin kullanımına ve endoskopistin tecrübe ve yeteneğine bağlıdır (1).

Transpapiller kanülasyon ERKP'de tercih edilen yöntemdir. Herşeye rağmen \%5 ila \%10 arası hastada ana safra kanalına girmek mümkün olmamaktadır, bu durumda pre-cut papillotomi veya iğne sfinkterotomi ile fistülotomiye ihtiyaç duyulmaktadır. Kanülasyon iğne sfinkterotomların kullanımının başlaması ile birlikte daha da başarılı olmuştur. (2-3). Biliyer kanülasyonu kolaylaştırmak için iğne sfinkterotomun kullanılması tartışmalıdır, çünkü eşlik eden yüksek risk ve morbiditeye sahiptir ki, bunlardan post ERKP pankreatit sıkça görülmektedir (4-6).

Periampüller bölge tümörlerinin tanı ve tedavisinde ERKP önemli yer tutmaktadır. Kısmi biliyer tıkanıklık nedeniyle hastalarda titreme, ateş ve sağ üst kadran ağrısının eşlik ettiği asendan kolanjit bulguları olabilir (7). Bu hastalarda safra yollarının drenajının yapılmasına ihtiyaç duyulabilmektedir.
Background and Aims: Endoscopic retrograde cholangiopancreatography is the gold standard for the diagnosis and treatment of biliary diseases. Direct access into the common bile duct is the most important step for successful therapeutic biliary endoscopy. Although transpapillary biliary cannulation is the preferred technique, it is not always possible. Therefore, suprapapillary cannulation has been developed as an alternative technique. Materials and Methods: Suprapapillary cannulation was performed in six patients determined to have periampullary tumor in the endoscopic retrograde cholangiopancreatography unit in our hospital. Results: No minor or major complications were observed during any of the operations. Conclusions: Especially when transpapillary cannulation is difficult in patients with periampullary tumor, the suprapapillary cannulation technique can be considered as an easy and safe method.

Keywords: ERCP, periampullary tumors, suprapapillary cannulation

Ancak periampüller bölge tümörlerinde kitlenin frajil ve kanamalı olması nedeniyle her zaman transpapiller kanülasyon gerçekleştirilememektedir. Bu hastalarda suprapapiller kanülasyon bir alternatif olabilir.

Çalışmamızda transpapiller kanülasyonun gerçekleştirilemediği periampüller tümörlerde suprapapiller koledok kanülasyonu yapılan hastalar değerlendirilmiştir.

\section{GEREÇ ve YÖNTEM}

Ocak 2008-Nisan 2013 tarihleri arasında sarılık nedeniyle hastanemize başvuran ve sarılık nedeni belli olmayan ancak manyetik reozonans kolanjiopankreatografide (MRKP) ampüller tümörden şüphelenilen 17 olgu ERKP ile değerlendirildi. Bu 17 olgudan kolanjit bulguları olan 8 hasta girişimsel işleme alındı. Tüm işlemler deneyimli tek bir endoskopist tarafından gerçekleştirildi. Yan görüşlü videoendoskop (Fujinon ED- 450XT5) ile kolanjiti olan 8 olgudan 2'sine transpapiller koledok kanülasyonu yapilabildi, ancak 6 olguda dokuların aşırı derecede frajil olması ve kanama nedeniyle transpapiller kanülasyondan vazgeçilip, suprapapiller bölgeden papilla ağzı ile transvers katlantı arasındaki çizginin 


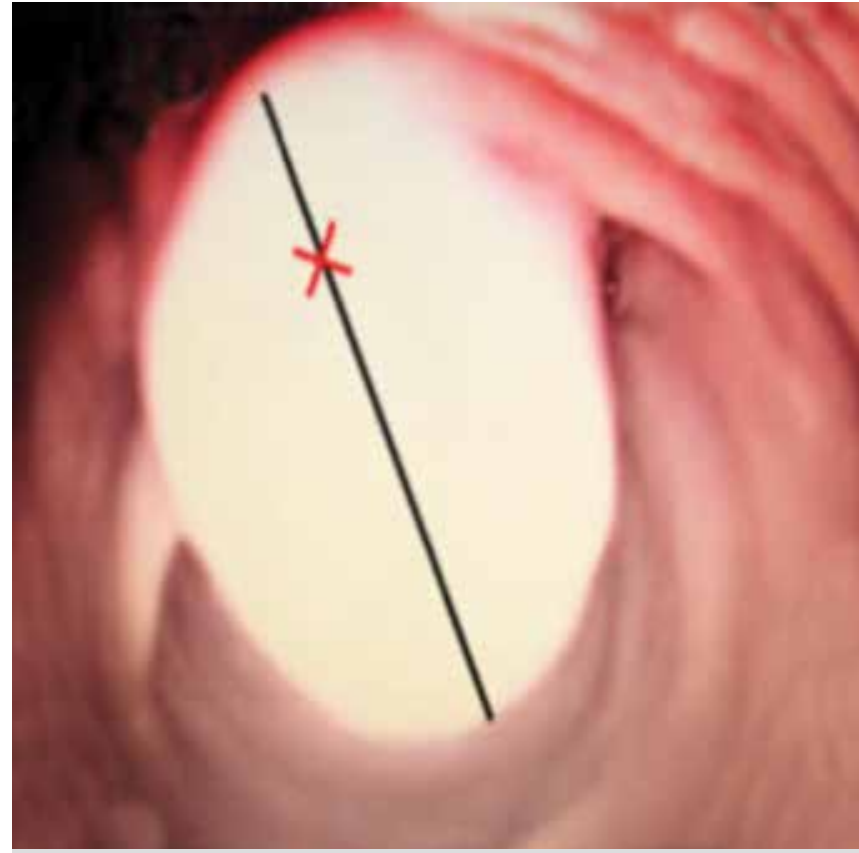

Resim 1. Suprapapiller kanülasyonun yeri.

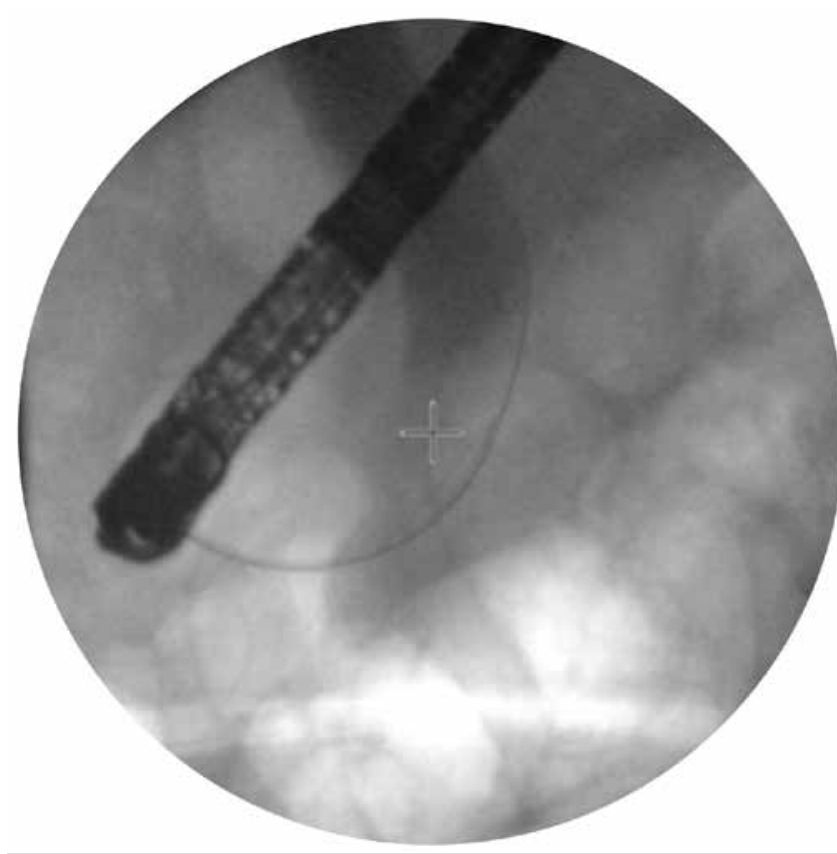

Resim 2. Suprapapiller kanülasyon yapılan ve kılavuz tel geçirilen hastanın ERKP görüntüsü.

1/3 proksimalindeki alandan iğne sfinkterotomi ile elektrokoagülasyon yapılarak kanülasyon gerçekleştirildi (Resim 1). Standart sfinkterotom ile girilerek kılavuz tel ana hepatik kanala gönderilerek kontrast madde ile koledok değerlendirildi (Resim 2), daha sonra 10 french 7 veya $9 \mathrm{~cm}$ 'lik plastik biliyer stent yerleştirildi (Resim 3).

Hastalardan patolojik inceleme için en az 3 adet biyopsi alın-

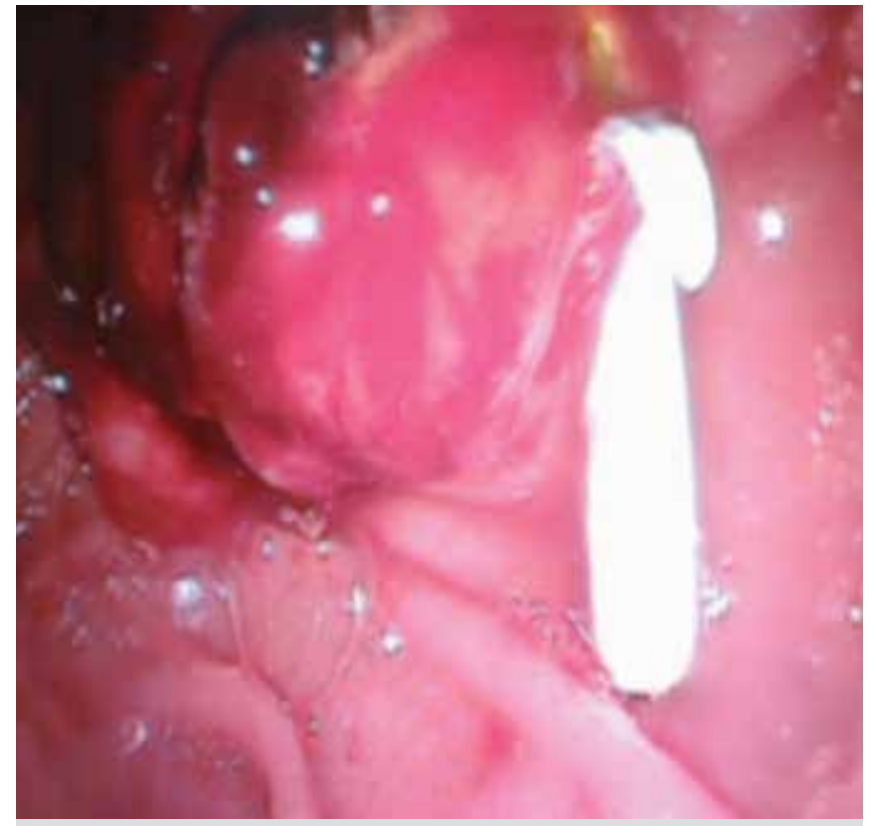

Resim 3. Transpapiller girişimin başarısız olduğu ve suprapapiller olarak yerleştirilen biliyer plastik stent.

d. Hastaların tamamı yatıılarak işlem sonrası komplikasyonlar (pankreatit, perforasyon ve kanama) açısından takip edildi. Suprapapiller kanülasyon yapılan 6 hasta yaş, cinsiyet, radyolojik bulguları, ERKP sonrası morbidite ve mortalite açısindan değerlendirildi.

\section{BULGULAR}

ERKP öncesi görüntüleme yöntemleriyle değerlendirilen hastaların tamamında koledok çapının $8 \mathrm{~mm}$ veya üzerinde olduğu belirtilmiști.

Hastaların ortalama yaş 61,5 ve erkek kadın oranı 1 idi. Hastaların 3'ünde pankreas başı tümörü, l'inde kolanjiokarsinom, l'inde ampüller adenom ve l'inde nöroendokrin tümör mevcuttu. Hastalar post-operatif 3 gün boyunca takip edildi. Pankreatit (karın ağrısı, bulantı veya kusmanın eşlik ettiği amilaz ve lipazın 3 kat arttığı durum), retroperitoneal perforasyon (retroperitoneal alana kontrast kaçması veya retroperitonda hava) veya kanama (minor kanama, endoskopik

\begin{tabular}{|c|c|c|c|c|c|}
\hline No. & Yaş & Cinsiyet & US (mm) & Patolojik Tanı & Komplikasyon \\
\hline 1 & 45 & K & 8 & Nöroendokrin tümör & Yok \\
\hline 2 & 67 & E & 10 & Pankreas adenokarsinom & Yok \\
\hline 3 & 69 & E & 9 & Pankreas adenokarsinom & Yok \\
\hline 4 & 72 & E & 12 & Pankreas adenokarsinom & Yok \\
\hline 5 & 59 & K & 10 & Kolanjiokarsinom & Yok \\
\hline 6 & 57 & K & 11 & Ampüller adenom & Yok \\
\hline
\end{tabular}


kontrolün mümkün olduğu ve hemodinaminin bozulmadığ , major kanama ise hematemez, melena, hemoglobinin $8 \mathrm{~g} /$ dl'nin altına düştüğü ve transfüzyon gerektiren durum) hastaların hiçbirinde görülmedi (Tablo 1). Hastaların tamamında 3 gün içerisinde kolanjit bulguları tamamen geriledi.

\section{TARTIŞMA}

Periampüller bölge tümörleri pankreas, duodenum, koledok alt ucu ve ampullayı içine alan bölgede gelişen neoplastik lezyonlardır (8). Duktal tıkanma semptomların ana kaynağıdır. Sarılık çoğunlukla açılır kapanır (intermitan) tarzdadır. Kısmi biliyer tıkanıklık nedeniyle hastalarda titreme, ateş ve sağ üst kadran ağrısının eşlik ettiği asendan kolanjit bulguları olabilir. Bu bulgular klinik sarılığı olmayan hastaların \%20'sinde de görülebilmektedir. Hastalarda asendan kolanjit bulgularının olması bu hastalarda biliyer drenaj yapılması gerekliliğini doğurur. ERKP biliyer drenajın sağlanması için en etkili ve güvenilir yöntemdir (7).

ERKP'de biliyer patolojinin değerlendirilmesi ve tedavisi için safra kanalının kanüle edilmesi ilk koşuldur. Son 30 yılda safra yoluna girilebilmesi için, hem kullanılan cihazlar hem de kullanılan tekniklerde gelişmeler olmuştur. Safra kanalı kanülasyonu için tercih edilen yöntem transpapiller kanülasyondur. Ancak değişik nedenlerden dolayı bu işlem her zaman başarılı olamamaktadır (9). Bu durumda alternatif olarak kullanılan suprapapiller iğne ponksiyon tekniği yeni tekniklerden biridir. Bir çalışmada suprapapiller teknik ile başarı oranının \%90 olduğu, kanülasyon için 5 dakikadan az süre gerektirdiği, minimal komplikasyona neden olduğu ve mortalitenin görülmediği belirtilmiştir. Aynı zamanda konvansiyonel transpapiller kanülasyon ve endoskopik sfinkterotomide görülen pankreatitin bu yeni teknikle ortadan kalktığı ifade edilmiştir. Bu teknikle pankreatik kanala kimyasal, alerjik, hidrostatik ve termal hasardan kaçınılmaktadır (10- 13).

Bir çalışmada çalışmanın başlangıcında \% 7 hastada perforasyon gelişmiştir. Kateterin ve kılavuz telin uygun yönlendirilmesi ve kontrastın yavaş enjekte edilmesi ile perforasyonun önlenebileceği tespit edilmiştir. Ayrıca bu çalışmada büyük taşların çıkartılması için balon dilatasyonu yapılması da bir neden olarak gösterilmiş ve büyük taşlarda mekanik litotripsi ile kırılarak taşların çıkartılmasının bu komplikasyonu engelleyebileceği belirtilmiştir. Hastalardan 2'sinde gelişen perforasyon sınırlı kalmış ve konservatif tedavi ile düzelmiştir. Özet olarak suprapapiller ponksiyon tekniği safra kanalının selektif kanülasyonu için başarılı bir tekniktir, pankreatik kanala olabilecek olan mekanik, kimyasal veya termal hasarı engeller, ancak yüksek komplikasyon hızına sahiptir. Bu çalışmada komplikasyon gelişen grup safra taşı nedeniyle girişim yapılan ve balon dilatasyon yapılan gruptur. Malignite nedeniyle girişim yapılan grupta herhangi bir komplikasyon gelişmemiştir. Bizim çalışmamızda da komplikasyon gelişmemesi bu çalışma ile açıklanabilir (10).

Bir başka çalışmada 2603 hastadan 317'sine suprapapiller iğne sfinkterotom ile başarılı kanülasyon gerçekleştirilmiştir. Fistülotomi yapılan hastalarda yapılmayanlara oranla komplikasyon hızı yüksek bulunmuştur (\%4,8'e karşılık \%2,1; $\mathrm{p}<0,001)$. Burada komplikasyon hızını artıran neden fistülotomi grubundaki hafif kanamadir. Ancak gruplar arasında pankreatit veya perforasyon açısından farklılık saptanmamış olup, fistülotomi sonrası mortalite görülmemiştir. Suprapapiller iğne ponksiyonu efektif bir yöntemdir. Hafif kanama hızı yüksek olmasına rağmen ciddi komplikasyon gelişme riski ile ilişkili değildir (14).

Bir başka çalışmada, 30 dakikalık süre içerisinde biliyer kanülasyon gerçekleştirilemediğinde suprapapiller fistülosfinkterotomi uygulanan hastalar değerlendirilmiştir. Ikinci endikasyon ise kolanjiogramda endoskopik sfinkterotomi gerektiren vakalarda kanülasyonun başarısız olması olarak belirtilmiştir. Papiller ağızın 3-5 mm proksimalinden işlem gerçekleştirilmiştir. 531 hastanın 83'ünde (\%16) suprapapiller fistülosfinkterotomi gerçekleştirilmiştir ve 74 (\%89) hastada başarılı olmuştur. Beş hastada (\%6) minor komplikasyon gelişmiştir. Mortalite görülmemiştir. Bu teknik önemli ve değerli bir tekniktir, ancak komplikasyon riski nedeniyle biliyer hastalık şüphesi olan ve endoskopik tedavinin gerekli olduğu hastalarda kullanılmalıdır (15).

Hashiba ve arkadaşları iğne sfinkterotom ve ince forsepsler kullanarak distal safra yolu endoskopik diseksiyon tekniğini tanımlamışlardır. Bu teknik 1057 girişimden başarısız olan 49 hastanın 48'inde kullanılmış ve tamamında başarılı olmuştur, 4 hastada klinik pankreatit 11 hastada ise hiperamilazemi görülmüştür. Perforasyon, kontrol edilemeyen kanama veya diğer komplikasyonlar görülmemiştir (16).

Sonuç olarak periampüller bölge tümörlerinde transpapiller kanülasyonun gerçekleştirilemediği durumlarda suprapapiller ponksiyon ile safra yolu selektif kanülasyonu ve stent yerleştirilmesi güvenli ve kolay bir yöntemdir, özellikle periampüller bölge tümörlerinde komplikasyon görülmemiştir.

\section{KAYNAKLAR}

1. Zhou PH, Yao LQ, Xu MD, et al. Application of needle knife in difficult biliary cannulation for endoscopic retrograde cholangiopancreatography. Hepatobiliary Pancreat Dis Int 2006;5:590-4.

2. Tang SJ, Haber GB, Kortan P, et al. Precut papillotomy versus persistence in difficult biliary cannulation: a prospective randomized trial. Endoscopy 2005;37:58-65. 
3. Catalano MF, Linder JD, Geenen JE. Endoscopic transpancreatic papillary septotomy for inaccessible obstructed bile ducts: Comparison with standard pre-cut papillotomy. Gastrointest Endosc 2004;60:557-61.

4. Laasch HU, Tringali A, Wilbraham L, et al. Comparison of standard and steerable catheters for bile duct cannulation in ERCP. Endoscopy 2003;35:669-74

5. Abu-Hamda EM, Baron TH, Simmons DT, Petersen BT. A retrospective comparison of outcomes using three different precut needle knife techniques for biliary cannulation. J Clin Gastroenterol 2005;39:717-21.

6. Freeman ML, Guda NM. Prevention of post-ERCP pancreatitis: a comprehensive review. Gastrointest Endosc 2004;59:845-64.

7. Yamaguchi K, Enjoji M, Kitamura K. Nonicteric ampullary carcinoma with a favorable prognosis. Am J Gastroentrol 1990;85:994-9.

8. Blumgart LH, Kennedy A. Carcinoma of the ampulla of Vater and duodenum. Br J Surg 1973;60:33-40.

9. Freeman ML, Guda NM. ERCP cannulation: a review of reported techniques. Gastrointest Endosc 2005;61:112-25

10. Artifon EL, Sakai P, Ishioka S, Hondo FY, Raju GS. Suprapapillary puncture of the common bile duct for selective biliary access: a novel technique (with videos). Gastrointest Endosc 2007;65:124-31.
11. Masci E, Mariani A, Curioni S, Testoni PA. Risk factors for pancreatitis following endoscopic retrograde cholangiopancreatography: a metaanalysis. Endoscopy 2003;35:830-4.

12. Elta GH, Barnett JL, Wille RT, et al. Pure cut electrocautery current for sphincterotomy causes less post-procedure pancreatitis than blended current. Gastrointest Endosc 1998;47:149-53.

13. Gorelick A, Cannon M, Barnett J, et al. First cut, then blend: an electrocautery technique affecting bleeding at sphincterotomy. Endoscopy 2001;33:976-80

14. Donnellan F, Zeb F, Courtney G, Aftab AR. Suprapapillary needleknife fistulotomy: a safe and effective method for accessing the biliary system. Surg Endosc 2010;24:1937-40.

15. O'Connor HJ, Bhutta AS, Redmond PL, Carruthers DA. Suprapapillary fistulosphincterotomy at ERCP: a prospective study. Endoscopy 1997;29:266-70.

16. Hashiba K, D'Assunção MA, Armellini S, et al. Endoscopic suprapapillary blunt dissection of the distal common bile duct in cases of difficult cannulation: a pilot series. Endoscopy 2004;36:317-21. 